\title{
Ex-Vivo Porcine Skin Model for Estimation of Trapped Occupant Burn Risk in Pre- and Post-suppression Fire Environments
}

\author{
Nicholas Traina, Richard M. Kesler and Gavin P. Horn, Illinois Fire Service \\ Institute, University of Illinois at Urbana-Champaign, MC-675, 11 Gerty \\ Drive, Champaign, IL 61820, USA \\ Nicholas Traina, Tonghun Lee and Gavin P. Horn, Mechanical Science and \\ Engineering, University of Illinois at Urbana-Champaign, $1206 \mathrm{~W}$. Green \\ St., Urbana, IL 61801, USA
}

Steve Kerber and Robin Zevotek, UL Firefighter Safety Research Institute, Underwriters Laboratories, Inc., 6200 Old Dobbin Lane-Suite 150, Columbia, MD 21045, USA

Received: 3 October 2018/Accepted: 31 May 2019

\begin{abstract}
There are currently important questions in the fire service as to the efficacy of various fire attack methods, both in terms of rapidly suppressing the fire and for potentially impacting the burn risk for occupants in the structure. A series of 24 full-scale residential fire experiments were performed to investigate the influence of fire size and fire service water application (interior only vs exterior-to-interior fire attack) on relative risk for skin burns in trapped occupants. A novel skin damage assessment tool utilizing ex vivo porcine skin samples was developed allowing measurement of temperatures at the surface of the porcine skin and at the subcutaneous fat surrogate interface. This tool allowed, for the first time, observation that typical fire attack methods resulted in short-lived transient increases in skin surface temperatures for a simulated occupant just outside the fire room that were typically around $5^{\circ} \mathrm{C}$ but ranged from $0^{\circ} \mathrm{C}$ to $15^{\circ} \mathrm{C}$ for rapid fire service intervention. Minimal differences were observed between the effects of interior or exterior fire streams immediately outside of the fire room. However, these values were markedly lower than when water application was delayed. This new tool provides novel information regarding trapped occupant skin burn risk that compliments traditional fire measurement tools and may provide a platform for future study on the impact of clothing as well as model based interpretation of experimental data that more accurately captures relevant physiology.
\end{abstract}

Keywords: Thermal burns, Fire suppression, Residential fires, Fire dynamics, Firefighting tactics

\footnotetext{
* Correspondence should be addressed to: Gavin P. Horn, E-mail: ghorn@illinois.edu
} 


\section{Introduction}

Occupants trapped within a residential structure during active fire are faced with life-threatening conditions due to the thermal risk as well as exposure to the irritant, toxic and asphyxiant smoke. While those close to the area of origin of the fire are at the highest risk for exposure to a thermal injury, those distant from the source may still be overcome by the fire gases. As a result, the fire service is called on to intervene as rapidly as possible to reduce both the thermal and gas threat through the application of water streams and ventilation of the structure. There are important questions in the fire service as to the efficacy of various hose stream application techniques, both in terms of rapidly suppressing the fire and for potentially impacting the burn risk for the occupants of the structure. Firefighters want to ensure that they are not unintentionally putting occupants at additional risk by upsetting the thermal layers or by creating excessive amounts of steam that could cause burns when in contact with bare skin.

In recent years, fire protection research has provided the fire service with several studies that have allowed a more detailed understanding of the fire dynamics of residential environments, including the effects of different ventilation tactics [1-5] and the relative effectiveness of different stream types [6-8]. Furthermore, firefighters may have the option to apply water to the fire from either the exterior or interior of the structure. Exterior initiated fire attack may provide the ability to apply water into the structure more rapidly (when conducted prior to structure entry) but may be limited in ability to reach the seat of the fire [9]. Interior water application requires entering the structure and may take longer, but this approach is more likely to allow direct access to the seat of the fire [10]. The "transitional fire attack" involves an initial exterior application of water through a ventilation opening near the seat of the fire in an attempt to improve conditions on the interior prior to entry, followed by an interior water application for final suppression (exterior-to-interior) [11]. While this tactical approach may provide a promising compromise for firefighters, there remains an important concern in the firefighting community that exterior and transitional attack may increase the threat of burns for trapped occupants as highlighted by recent trade journal articles [12, 13] as well as recommendations in common fire service tactics handbook [14]. In practice, the hazard of fire service hose streams increasing risk for burns in trapped occupants is likely highest for those who have been incapacitated by toxic gasses while breathing air at higher elevations in the compartment (and have fallen to the ground without fatal dose) or for occupants who had been protected by compartmentation that either failed during the fire or as the occupant attempted to self-evacuate from that compartment and was no longer protected during firefighting activities.

Prior to adopting a method that may differ from what they have used in the past, the fire service requires valid evidence to better understand the influence of water application to a "room and contents" fire on trapped occupant exposure-particularly with respect to changing the risk for burns. Traditional measurement techniques utilized to estimate thermal risk include thermocouples to measure air temperature and heat flux gauges to characterize the thermal energy 
available to increase temperature of surfaces such as skin. These devices can be utilized to estimate thermal exposures through techniques such as the ISO standard fractional effective dose (FED) tenability method. Large-scale studies have examined room and contents fires through the lens of occupant tenability using the FED methodology outlined in ISO 13571 [15]. The relative impact of toxic gases and heat has been examined in constructed rigs for compartments [16], single family residential structures [8, 17], one-bedroom apartments [18], and basement fires [19]. These studies reinforce anecdotal evidence that the most significant risk for occupants in the fire room or close to the fire is from thermal injuries, while those distant from the fire typically experience an increased risk from toxic gases. Intermediate distances are of interest, particularly where the thermal injury and gas exposures may not reach untenable levels and the fire service intervention may affect survivability for trapped occupants.

However, there exist some important limitations to the FED approach. Thermal FED techniques based on air temperature (as measured by thermocouples) do not account for local velocity that can impact heat transfer, nor do they account for the effects of radiant heat. Radiation can have significant impacts on trapped occupants and operating firefighters; for example polycarbonate materials used in firefighting PPE have been shown to soften and damage even when the local air temperature averages $40^{\circ} \mathrm{C}$, which was attributed to the significant radiant heat exposure [20]. Alternate FED methodologies exist that utilize heat flux measurements, but common laboratory heat flux gauges are limited when significant moisture is present in the environment. This limitation is of particular concern when attempting to characterize impact of fire service hose streams. Furthermore, the interaction between the metallic heat flux gauges and the complex environment may be much different than that experienced by skin since radiant flux is highly dependent on the emissive characteristics of the surrounding environment, and the skin's interaction with radiant heat varies with the spectral characteristics of the incident radiant flux $[21,22]$. The FED methodologies are also limited by their use of correlation equations and thus inherently involves a large amount of uncertainty. Finally, interpretation of FED tenability criteria in terms of skin damage and relative risk can be challenging due, in part, to the complexity of the progression of burn damage in the skin.

Skin is comprised of two distinct layers above the subcutaneous fat layer. The epidermis is the outer layer of skin with a thickness that typically ranges from $50 \mu \mathrm{m}$ to $120 \mu \mathrm{m}[23,24]$, though can be much thicker on palms of the hand or soles of the feet $[25,26]$. This layer of skin is comprised of dead cells and acts as the protective barrier to harmful environmental conditions such as moisture, ultraviolet radiation, and extreme heat [23]. The dermis is the second layer of skin $(\sim 500 \mu \mathrm{m}$ to $\sim 5000 \mu \mathrm{m}$ based on body site $[23,27])$ which contains important living tissues such as blood vessels and nerve endings. Classification of burn injuries has historically taken many forms, but usually considers the involvement of one or both skin layers and potentially deeper tissues such as subcutaneous fat, muscle and/or bone [28-30]. Commonly, burns are considered 'first-degree' if only the epidermis is affected (superficial epidermal injury). 'Second-degree burns' occur when the damage reaches the dermal layer and are sometimes separated 
into 'superficial partial thickness' that involve the papillary dermis and 'deep partial thickness' second-degree burns that extend into the reticular dermis. 'Third-degree' or 'full-thickness' burns involve the full depth of the dermis and may begin to impact deeper tissues. Additional burn damage classifications may include 'fourth-degree' burns that involve subcutaneous fat and even 'fifth-degree' (muscle) or 'sixth-degree' (bone) [29].

To support deeper understanding of the relative impact of firefighting tactics and techniques on trapped occupant skin burn risk, it is desirable to develop a technique that can provide a biologically relevant estimate of skin burn risk without the limitations of the current instrumentation and numerical methodologies. Ethical and logistical concerns limit the ability to use live human or animal models in such experiments. However, there is promise in utilizing an ex vivo porcine skin model to provide a viable, flexible, and logically interpretable means on which to estimate human burn risk. Domestic pigs have been used for decades as surrogates for humans in experiments. The skin of a domestic pig is similar to humans in many aspects such as thickness, structure, and composition [31]. Pig skin and human skin both have similar proteins, a sparse hair coat, a thick epidermis, a dermis with a papillary body, a deep layer of subcutaneous fat, and a large amount of elastic tissue [32]. Normal pig skin varies by body site just as human skin does. The pig epidermis is described as ranging in thickness from $70 \mu \mathrm{m}$ to $140 \mu \mathrm{m}$, which compares well with the human epidermis range [33]. Due to the range of skin thickness throughout the body, a dermal-epidermal ratio ranging from 10:1 to $13: 1$ proves to be a better measure of thickness and is again, comparable in both pig and human skin [34]. It has been suggested that the structure of the pig's skin is so similar to that of a human, that it may be a superior model than that of nonhuman primate skin [35]. However, there are important differences such as a lower water loss from pig skin at elevated temperatures and lack of blister formation that must be considered when using this model.

In the 1940s, Moritz and Henriques conducted a series of experiments with both humans and pigs, where they created contact burns at different temperatures and durations of time [31, 36]. Through these experiments, it was discovered that irreversible damage will occur to the epidermis when the surface of skin reaches $44^{\circ} \mathrm{C}$, although it can take long periods of exposure. Below this temperature, transfer of heat away from the skin is rapid enough to reduce the risk of damage due to burning. It was noted that irreversible damage at the deep dermal (basal) layer did not occur until approximately six hours of exposure to surface temperatures of $44^{\circ} \mathrm{C}$. However, the time required to create irreversible damage is reduced by about half with every degree increase between $44^{\circ} \mathrm{C}$ and $51^{\circ} \mathrm{C}$. If the surface temperature is raised to $70^{\circ} \mathrm{C}$ or higher, skin damage occurs so quickly that necrosis of the epidermis can take place in less than one second. Stoll and Green continued the work of Moritz and Henriques and studied the implication of the skin damage model using a first order chemical reaction rate equation [37]. Importantly, Stoll and Green discussed that the destruction of the skin does not only begin when the surface rises above $44^{\circ} \mathrm{C}$, but continues as long as the temperature of the layer is maintained above $44^{\circ} \mathrm{C}$. Thus, the impact of cooling skin to below this level also needs to be included in damage prediction methods. With the use of 
this approach, burn injury becomes a function of the time and temperature that the skin exceeds $44^{\circ} \mathrm{C}$.

The goal of this study was to characterize the relative risk for skin damage in occupants trapped in structure fires with a specific focus on how this risk is impacted by fire attack method. To accomplish this goal, twenty-four experiments were performed in a full-scale residential structure and a new approach utilizing an ex vivo biological model of porcine skin was implemented in five locations throughout the structure. Skin surface temperatures are measured throughout fire growth and post suppression as the environment responds to water application end eventually cools to ambient. Local air temperatures and heat flux measurements were collected at each location to compare and contrast skin surface temperatures to traditional measurements commonly used for estimating skin damage risk.

\section{Experimental Sełup}

A series of 24 experiments were performed at UL's large fire lab in Northbrook, IL [38]. A $150 \mathrm{~m}^{2}$ single-story structure was built with a total of six rooms (four bedrooms, one living room, and one dining room) and an extended hallway. Each bedroom had a doorway entering into the hallway, and a removable insert for a window opening to the exterior of the structure. The floor plan of the structure with furnishings, initial fire locations, simulated occupant locations, and instrumentation relevant to this manuscript is presented in Fig. 1. A complete description of the experimental details and significant additional data collected during this experimental campaign can be found in reference [38].

Three different fire scenarios (Test Types) were studied in this project. Test Type 1 was conducted with a fire in Bedroom 1, the bedroom window closed and a flow path from the fire room to the front door (to allow firefighters to enter and suppress) created $7 \mathrm{~min}$ to $9 \mathrm{~min}$ after ignition. Test Type 2 was similar to Test Type 1, but the Bedroom 1 window was open for the duration of the experiments and entry was made to the structure $5 \mathrm{~min}$ to $7 \mathrm{~min}$ post-ignition. For Test Type 3 , fires were simultaneously ignited in both Bedroom 1 and Bedroom 2, with both bedroom windows open, and the front door opened $5 \mathrm{~min}$ to $7 \mathrm{~min}$ after ignition. Within each group of scenarios conducted for all three Test Types, two different fire attack methods were employed (interior only, exterior-to-interior), with slight differences in the technique implemented for water application. During the experimental study, different patterns (e.g. straight stream vs. narrow fog) and hose advancement technique (e.g. 'flow and move' vs. 'shut down and move') were consistently implemented for each Test Type. For the most part, these small differences had little impact on the environment or on the pattern of response where skin burn assessments were taking place. However, the sample size was too small to make any meaningful conclusions regarding the effect of those differences in technique. Furthermore, because the study was aimed at analyzing how water application affects the fire environment, some of the water application techniques implemented are not recommended by the authors and were only performed to 


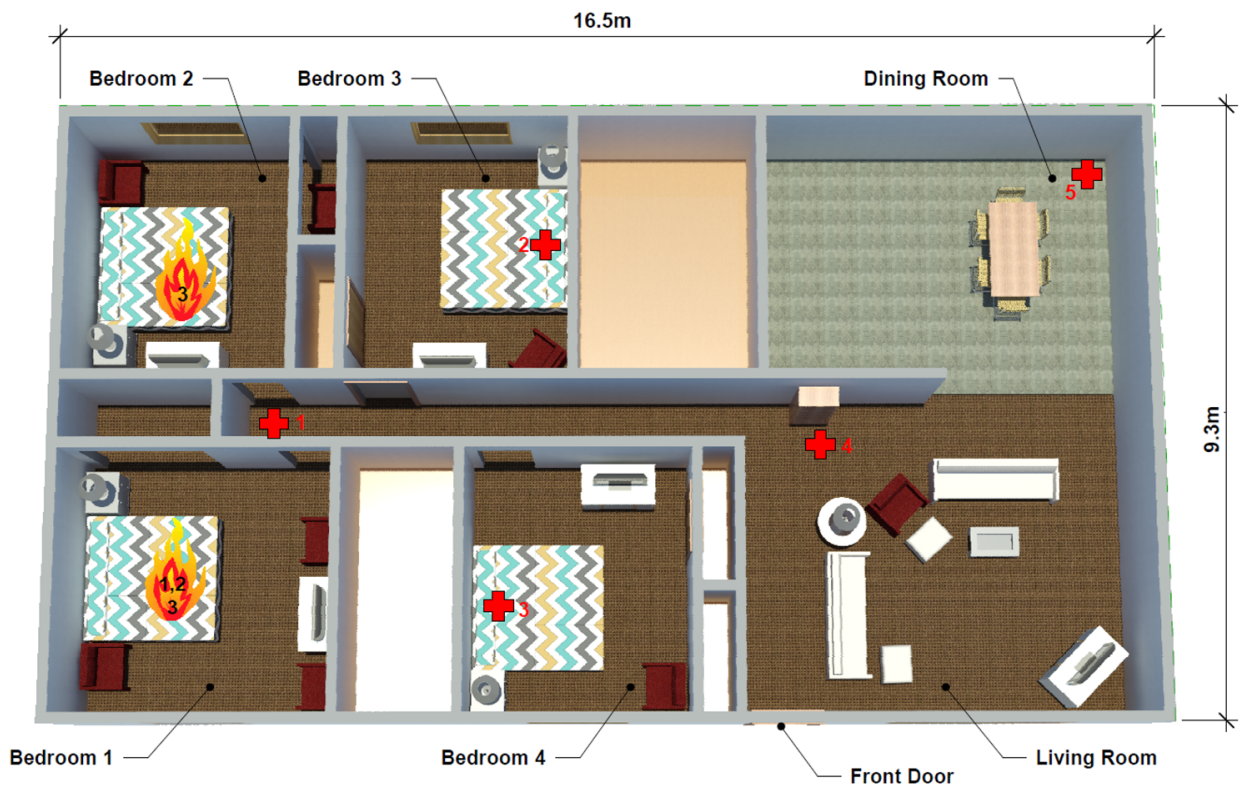

\begin{tabular}{|c|c|c|c|c|c|c|}
\hline \multirow[b]{2}{*}{$\begin{array}{l}\text { Test } \\
\text { Type }\end{array}$} & \multicolumn{2}{|c|}{ Fire Scenarios } & \multicolumn{2}{|c|}{ Number of Experiments } & \multirow{2}{*}{$\begin{array}{c}\text { First Water } \\
\text { (m:ss) } \\
\text { Ave (Range) }\end{array}$} & \multirow{2}{*}{$\begin{array}{c}\text { Delayed Water } \\
\text { Scenario } \\
\text { (m:ss) }\end{array}$} \\
\hline & Fire Room & Ventilation & $\begin{array}{c}\text { Interior } \\
\text { Only }\end{array}$ & $\begin{array}{l}\text { Exterior-to- } \\
\text { Interior }\end{array}$ & & \\
\hline 1 & om 1 & $\mathrm{~N}$ & 6 & 0 & $8: 02(7: 23-8: 32)$ & $27: 50$ \\
\hline 2 & Bedroom 1 & Bedroom 1 & 6 & 4 & $6: 06(5: 24-6: 52)$ & $13: 32$ \\
\hline 3 & Bedroom $1 \& 2$ & Bedroom $1 \& 2$ & 5 & 3 & $5: 48(5: 26-6: 43)$ & $10: 36$ \\
\hline
\end{tabular}

\section{Figure 1. Floor plan (approximately to scale) with locations of furnishings, skin burn assessment (SBA) package at simulated trapped occupant locations (red crosses numbered 1 to 5) and fire location for each Test Type (\# 1 to 3) (Color figure online).}

compare with more reasonable and typical water application techniques. In a few isolated cases, comments will be made where important outcomes are noted based on these technique differences, but detailed study of technique is beyond the scope of this manuscript.

In order to measure gas temperature throughout the structure, Type $\mathrm{K}$, bare bead ( $0.5 \mathrm{~mm}$ nominal diameter) chromel-alumel thermocouples were deployed at several locations shown in Fig. 1. These thermocouples measured temperatures at $0.3 \mathrm{~m}, 0.9 \mathrm{~m}, 1.5 \mathrm{~m}$ and $2.1 \mathrm{~m}$ above the floor. Identical thermocouples were also utilized for surface and subdermal temperature measurements for the skin burn assessment packages as indicated below. Thermocouple uncertainty is less than 1 to $2 \%$ of the measured values up to $977^{\circ} \mathrm{C}$ [39].

Medtherm 64-10SB-20 heat flux gauges, capable of measuring combined conductive, convective, and radiative flux, were used to measure the heat flux in the hallway outside the fire rooms and at each simulated occupant location. The uncertainty given by the manufacturer was $\pm 3 \%$ of the measured value and the sensor has an average radiative absorptance of 0.95 for $0.6 \mu \mathrm{m}$ to $15 \mu \mathrm{m}$. 


\subsection{Skin Burn Assessment (SBA) Package Description}

A new method for estimating skin burn risk based on ex vivo samples of porcine skin was developed to support these experiments. Figure 2 shows the design and instrumentation of the skin burn assessment (SBA) package experimental setup. While there are important limitations to using an ex vivo model, such as a lack of perspiration (a limitation of any porcine model) and no skin perfusion, the number of samples needed for this large-scale study (five locations over 24 scenarios would require 120 animals) and the limitation of using live animal models required such an approach. Furthermore, the SBA tool provides significant advantage over methods that utilize porcine carcass [e.g. 40] approach by harvesting only the skin. By not freezing the full carcass, defrosting and controlling temperatures - particularly core temperatures - at biologically reasonable levels is possible. The SBA package is an easily transportable technique for estimating the impact of skin samples exposed to live-fire conditions in a repeatable set up.

Five excised porcine skin samples (surrogate for human epidermal and dermal layers) are introduced on top of $9.5 \mathrm{~mm}$ thick ethylene propylene diene monomer (EPDM) rubber slabs (surrogate for subcutaneous fat), which float on top of a basin holding water at $36^{\circ} \mathrm{C}$ to $38^{\circ} \mathrm{C}$ (to simulate the core of the body). Each exposed skin sample was $10 \mathrm{~cm} \times 10 \mathrm{~cm}$ to allow generalization of a one-dimensional heat transfer scenario through the skin. EPDM was used for subcutaneous fat as it has similar thermal conductivity and heat capacity of subcutaneous fat while being only slightly more dense as well as providing a repeatable and uniform thickness. The thickness of the EPDM was selected to simulate the thickest layers of subcutaneous fat. The back side of the EPDM was in contact with the water bath, providing a controlled thermal boundary condition. Strips of ceramic insulation were used to cover the exposed aluminum on the top of the support tray. Fiberglass insulation was wrapped around the basin to focus heat transfer

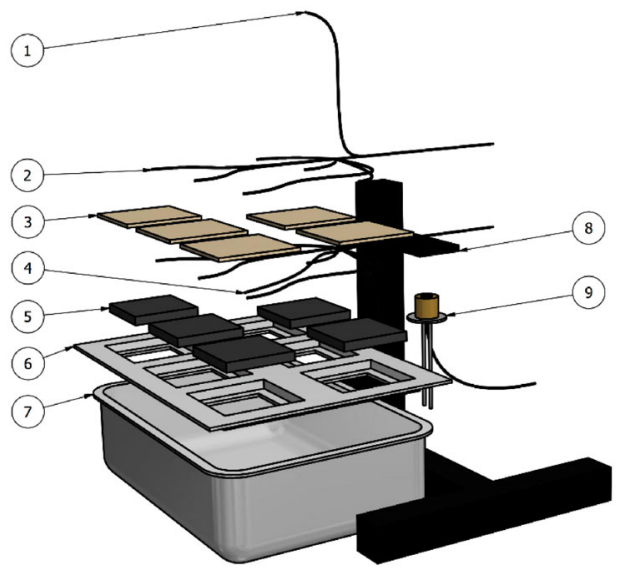

\begin{tabular}{|c|c|c|}
\hline \multicolumn{3}{|c|}{ SBA Package Components } \\
\hline ITEM & QTY & DESCRIPTION \\
\hline 1 & 1 & Air Thermocouple \\
\hline 2 & 2 & Thermocouple Bundle \\
\hline 3 & 5 & Skin \\
\hline 4 & 1 & $\begin{array}{c}\text { Water Bath } \\
\text { Thermocouple }\end{array}$ \\
\hline 5 & 5 & EPDM \\
\hline 6 & 1 & Support Tray \\
\hline 7 & 1 & Reservoir \\
\hline 8 & 1 & Heat Flux Mount \\
\hline 9 & 1 & Heat Flux Gauge \\
\hline \multicolumn{3}{|c}{} \\
\hline
\end{tabular}

Figure 2. Exploded CAD view of SBA experimental design with parts list. 
into the system through the skin surrogate, which allowed the water bath to maintain a temperature at physiologically valid human core body levels.

Type $\mathrm{K}$ thermocouples were attached to the surface of the EPDM layer using cyanoacrylate glue to measure subdermal temperature. An identical thermocouple was placed in the center on the surface of the skin sample after it was deployed. Additionally, thermocouples were used to measure the temperature of the air surrounding the SBA packages and to monitor the temperature of the water bath during the test to ensure simulated core body temperature was closely maintained. Vertically oriented heat flux gages were deployed at each location to measure the thermal energy reaching the skin samples.

\subsection{Sample Preparation and SBA Deployment}

Porcine skin samples were collected from research animals at the University of Illinois after they were euthanized for purposes unrelated to this project. The dermal and subcutaneous fat layers were removed immediately from the carcass. After transportation to the lab, subcutaneous fat was removed, the hair was shaved and approximately $10 \mathrm{~cm} \times 10 \mathrm{~cm}$ samples were excised. Each sample was then sealed in an individual plastic bag and stored in a freezer until the live-fire scenarios were to be conducted. Before being deployed into an experiment, the skin was thawed in the plastic bags using a water bath held at $35^{\circ} \mathrm{C}$ to $40^{\circ} \mathrm{C}$ approximately $1 \mathrm{~h}$ before the experiment began. After the sample was fully thawed, the skin was removed from the bag and its thickness was measured (MTG-DX2, Schultes Precision Mfg). Skin samples were placed on a flat pan with a damp towel covering the surfaces to keep the sample from drying out. The samples were then deployed to their locations and attached to the EPDM blocks using cyanoacrylate glue, with surface thermocouples fastened in a similar manner. Damp towels were then placed over the specimens until testing began while submersible water heaters and pumps were used to control the water bath temperature and provide continuous water circulation. Approximately $2 \mathrm{~min}$ to $5 \mathrm{~min}$ before the experiment began, the towels were removed and the doors and windows of the structure were closed as appropriate. Air temperatures in the lab were typically between $15^{\circ} \mathrm{C}$ and $25^{\circ} \mathrm{C}$ and the surface temperature of the skin was generally between $27^{\circ} \mathrm{C}$ and $33^{\circ} \mathrm{C}$ at the start of the experiment.

The SBA packages were deployed at five locations in the test structure (Fig. 1) at two different heights as described in Table 1. The SBA packages at the $0.2 \mathrm{~m}$

\section{Table 1}

SBA Number Designation and Sample Height for the Different SBA Package Locations

\begin{tabular}{llc}
\hline SBA location & \multicolumn{1}{c}{ Location description } & Height (m) \\
\hline 1 & End of hallway between bedroom 1 and 2 & 0.2 \\
2 & In the closed door bedroom (Bedroom 3) on the bed & 0.9 \\
3 & In the open door bedroom (Bedroom 4) on the bed & 0.9 \\
4 & At the beginning of the hallway in the living room & 0.2 \\
5 & In the corner of the dining room & 0.2 \\
\hline
\end{tabular}



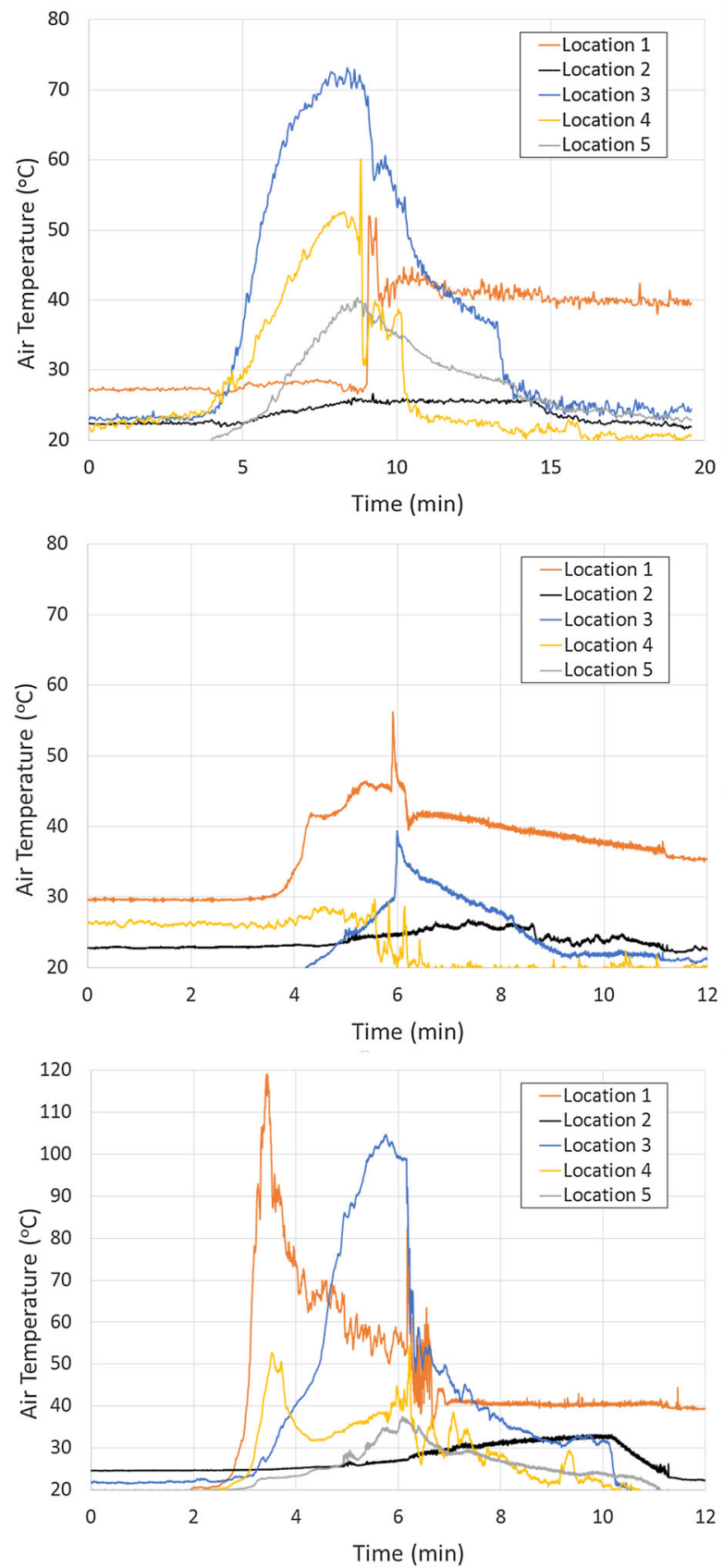

Figure 3. Air temperatures measured at each of the five SBA locations for Test Type 1 (top), Test Type 2 (middle) and Test Type 3 (bottom, note different temperature scale). 
height were placed on the floor of the structure to simulate an incapacitated occupant lying on the ground. The SBA packages deployed at the $0.9 \mathrm{~m}$ location were placed on top of a typical queen-sized bed (with metal frame, box spring, and mattress) in order to simulate a sleeping occupant. The bedroom door at the entrance to Location 2 was closed throughout each burn while door leading into Location 3 (and each of the fire rooms) was left open. Typical environmental temperatures at each of the five locations for the three different Test Types are provided in Fig. 3.

\section{SBA Results and Discussion}

\subsection{Typical Skin and Environmental Thermal Data}

Multiple skin samples are deployed at each location in order to ensure consistency in measurement and to provide several data points in case a single thermocouple fails. To ease visualization of typical data trends, average surface and subdermal temperatures are plotted along with the local ambient air temperature and heat flux collected by the SBA tool in Fig. 4 at Location 1 (hallway just outside of the fire $\operatorname{room}(\mathrm{s})$ ) and Location 3 (on bed in room down the hallway (Bedroom 4)) for an example Test Type 1 experiment. The standard deviation of surface temperatures is, on average, by $1.3^{\circ} \mathrm{C}\left(\max\right.$ standard deviation $\left.2.9^{\circ} \mathrm{C}\right)$ at Location 1 and $1.3^{\circ} \mathrm{C}$ ( $\max$ standard deviation $3.2^{\circ} \mathrm{C}$ ) at Location 3 over the course of the experiment. For the first couple of minutes, as the fire begins to build, the highest recorded temperatures are from the water basin ('core temperature'-not shown here), followed by the subdermal thermocouples. Thermcouple readings on the skin surface are between sudbdermal and air temperature as expected. Once the SBA packages begin to receive radiant heating from the growing fire $\left(1 \mathrm{~kW} / \mathrm{m}^{2}\right.$ to $2 \mathrm{~kW} / \mathrm{m}^{2}$ ), the surface temperatures begin to rise. By four minutes, the surface temperatures have exceeded the subdermal temperatures and shortly thereafter, these values exceed core temperature. In this specific scenario, the surface temperatures begin to level off for about $3 \mathrm{~min}$. The delivered heat flux is sufficient to hold the skin temperatures at around $42^{\circ} \mathrm{C}$, as heat transfer dissipates this energy deeper into the tissue. As such, the subdermal temperatures begin to rise over time. In this scenario, air temperature remains fairly constant until the firefighters' water application. Shortly after water is flowed down the hallway to begin the fire attack, a significant jump in temperatures is measured by the surface thermocouples as well as the air thermocouple at Location 1. Skin surface temperatures are increased to above $49^{\circ} \mathrm{C}$ for approximately $15 \mathrm{~s}$ before rapidly cooling as water continues to be flowed by the fire suppression stream. By the end of the experiment, the highest temperatures are measured at the subdermal level as the surface appears to have been cooled through water contact.

With heat flux data (green line, secondary vertical axis) overlaid on the temperature plots, it is clear that the initial skin temperature rise at Location 1 is driven 

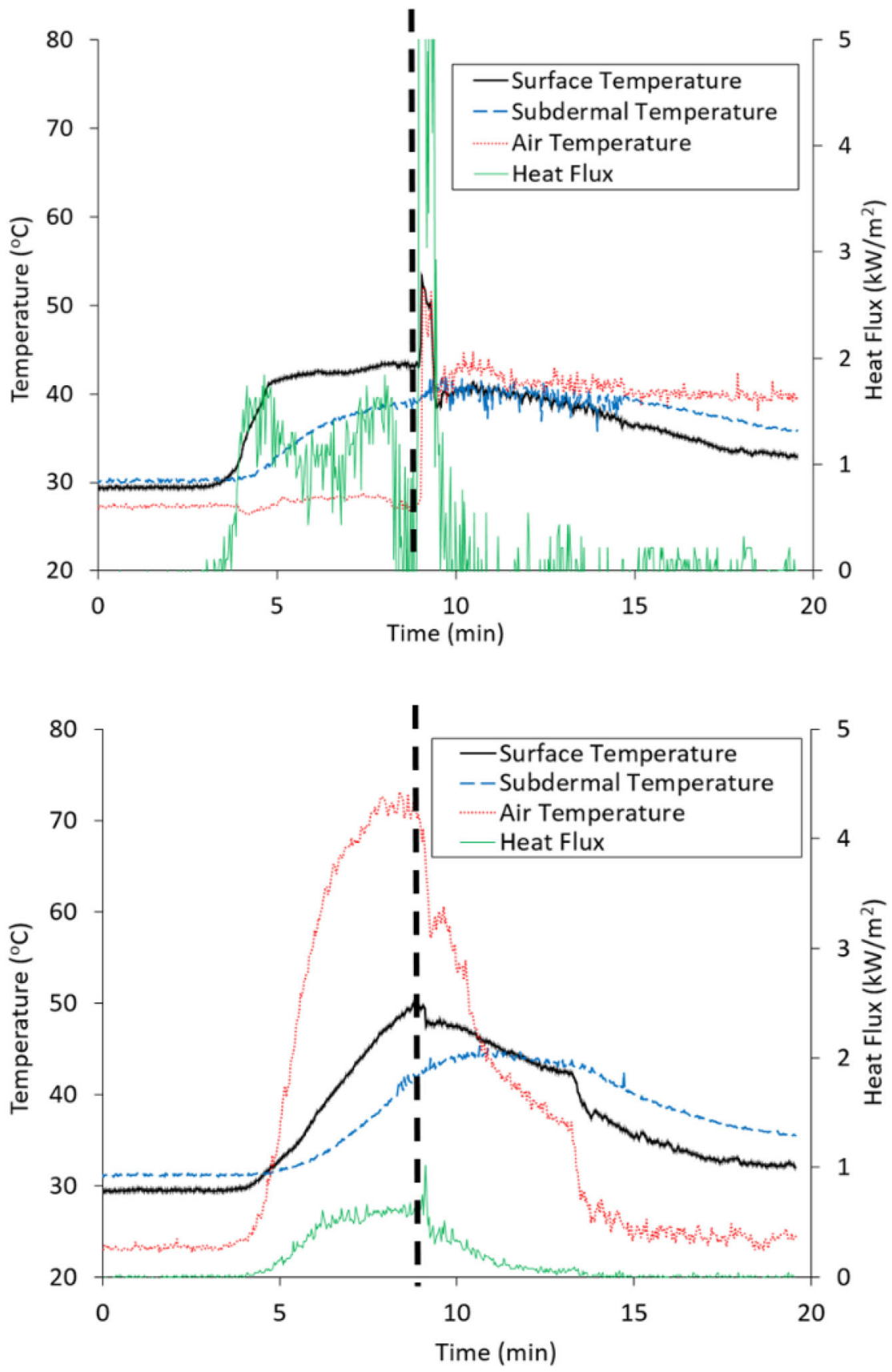

Figure 4. Average surface and subdermal temperature along with air temperature and local heat flux for Test Type 1 at SBA Location 1 (top) and Location 3 (bottom). Black dotted line shows water application time. 
largely by the radiant energy from the growing fire as opposed to convection. The local ambient air temperature never exceeds the skin surface temperature until after suppression. When water is applied around $9 \mathrm{~min}$ after ignition, the temperature of the skin surface and air temperature rapidly increase in concert. Several potential mechanisms may be responsible for these transient increases in temperature, most likely attributable to increased mixing in the fire environment that would lead to descent of the hot upper gas layer, contact with steam or hot water from suppression sprays, and/or condensation onto the cooler surfaces in the lower layer. Prior to water application, the skin temperatures were typically below the $44^{\circ} \mathrm{C}$ threshold for burn damage to occur, but the levels reached after water application were, in some cases, high enough to begin the damage process of the surface layers and possibly into the thickness of the skin. Fortunately, this spike in temperatures was short lived as the firefighters continued to flow water and cool the environment. During the suppression phase, the heat flux measured at Location 1 typically shows a spike, often to unrealistic values (in this case reaching nearly $32 \mathrm{~kW} / \mathrm{m}^{2}$ ). Thus, while the trends in skin temperatures match that of the heat flux more closely than air temperature, it was not possible to accurately estimate useful skin temperature estimates with heat flux measurements.

At Location 3, the measured heat flux is below $1 \mathrm{~kW} / \mathrm{m}^{2}$ throughout the fire event and it is not likely that significant radiation from the flames would reach this SBA package due to the configuration of the structure. However, as this SBA package is sitting on top of a bed (at $\sim 0.9 \mathrm{~m}$ from the ground), the hot upper gas layer-without any significant ventilation to the exterior of the structure-descends to this level, raising local air temperatures to over $70^{\circ} \mathrm{C}$. In contrast to the skin surface and air temperatures that peaked abruptly at Location 1 after water application, these values decrease sharply at Location 3. Heat flux measurements at this location do show a small but noticeable spike after water application, possibly due to condensation on the cooled gauge from moisture in the upper gas layer as it descends into the structure. In this case, the skin surface temperature follows the gas temperature trends more closely than the heat flux trends. Although the SBA measurements at Location 1 peaked at a higher surface temperature than at Location 3, the longer duration exposures to high ambient temperatures resulted in more substantially elevated subdermal temperatures at Location 3. This fact again highlights that the skin burn risk potential is both a function of temperature of the skin and the length of time the skin is at that temperature.

Figure 5 shows similar SBA tool generated information as Fig. 4, but for an example scenario from Test Type 2. At Location 1, significantly higher heat flux is measured at the beginning of the fire ( $3 \mathrm{~min}$ to $5 \mathrm{~min}$ after ignition) as the window vent allows smoke to exit the building and supports well ventilated combustion for a longer period of time. With the fire room window initially ventilated, there is enough oxygen supplied to the fire room to allow the compartment to transition to flashover. Though fire attack occurs sooner than in Test Type 1, the SBA temperature profiles are relatively similar. While water is being flowed down the hallway for suppression (approximately six minutes after ignition), the surface temperature spikes to around $52^{\circ} \mathrm{C}$, though for only a few seconds. After suppres- 

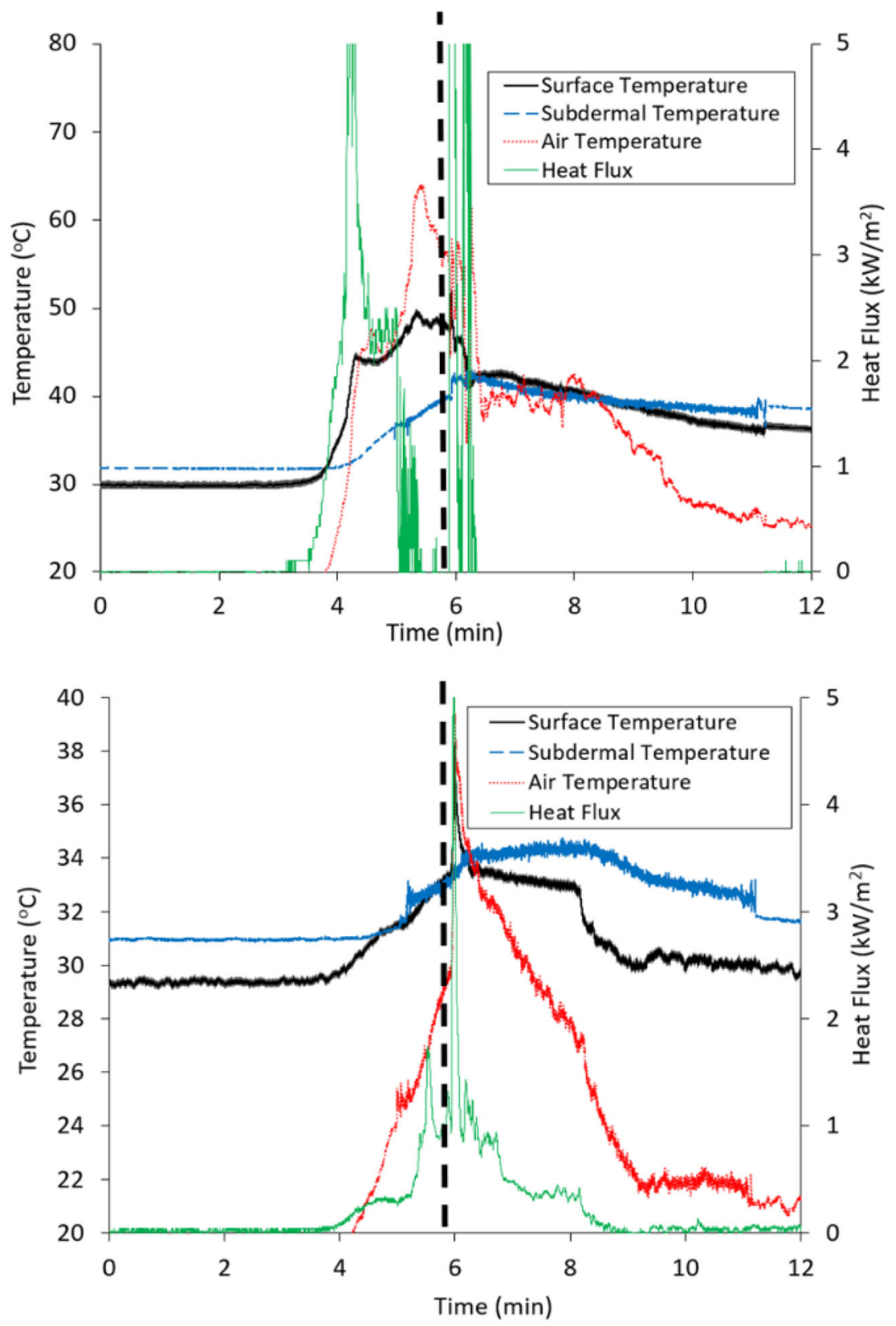

Figure 5. Average surface and subdermal temperature along with air temperature and local heat flux for Test Type 2 at SBA Location 1 (top) and Location 3 (bottom). Black dotted line shows water application time. At Location 1 , peak heat flux prior to suppression (at around $4 \mathrm{~min}$ ) reaches $6.0 \mathrm{~kW} / \mathrm{m}^{2}$. 
sion, the skin surface temperature begins to drop and eventually returns to levels below subdermal values. Once again, the heat flux values measured during suppression reach magnitudes that are not realistic (peaking near $37 \mathrm{~kW} / \mathrm{m}^{2}$ ) and would suggest a significant increase in skin temperatures while the measured values are actually declining.

At Location 3, the ambient air and skin temperatures 6 min after ignition are lower than in Test Type 1. With the window initially ventilated, the hot fire gases are able to exhaust out of the fire compartment, such that the descent of the smoke layer in the rest of the structure is slower than if there were no ventilation. Skin temperature remains above ambient temperatures prior to suppression. Surface temperatures begin to increase around $4 \mathrm{~min}$ when radiation from the hot upper gas layer - though relatively small - begins to deliver energy to the skin. Again, after water application, a $\sim 5^{\circ} \mathrm{C}$ spike in surface temperature is measured at Location 3 as the ambient air temperature and heat flux increases dramatically, though for a short period of time. While the magnitude of this surface temperature increase is larger than at Location 1, the magnitude of the initial skin temperature was much lower. Thus, this increase, though likely to be perceived and possibly uncomfortable to the occupant, is not likely to increase burn risk as skin temperatures never exceeded $40^{\circ} \mathrm{C}$. Outside of the water suppression induced peak in surface temperature, the subdermal readings remained higher than or equivalent to the surface throughout. This data set highlights the sensitivity of the SBA approach to detecting the impact of small changes in environmental conditions on the skin temperatures.

Finally, Fig. 6 shows the same SBA tool output at Locations 1 and 3 for a representative Test Type 3 scenario. For Test Type 3, the standard deviation of the surface temperatures was, on average, $1.9^{\circ} \mathrm{C}$ (max standard deviation was $10.7^{\circ} \mathrm{C}$ ) at Location 1 and $1.3^{\circ} \mathrm{C}$ (max standard deviation $3.2^{\circ} \mathrm{C}$ ) at Location 3. The likely reason for the relatively large variability at Location 1 for the Test Type 3 scenarios, is that the view factor from the skin samples to the two rooms can vary significantly. Additionally, at this location near the fire, falling debris (ash, damaged drywall, charred fuel, etc.) would often land on only a few of the samples. This latter affect was more common in the intense Test Type 3 fires than in Test Type 1 or 2 fires.

Due to the large, radiant fire with heat flux values at Location 1 briefly exceeding $30 \mathrm{~kW} / \mathrm{m}^{2}$, skin surface temperatures reach above $110^{\circ} \mathrm{C}$ in less than $4 \mathrm{~min}$ after ignition. Due the presence of two fully involved bedrooms with exterior ventilation, both rooms transition to flashover. Typically in the Test Type 3 scenarios, flames will intermittently enter the hallway from the bedrooms underneath the smoke layer as long as there is enough oxygen remaining in the attached compartment, resulting in high radiant flux to the floor in this location. However, once oxygen levels are reduced in the hallway, flaming combustion is no longer supported at this location and flames are only seen at the exterior vent location. This high intensity heat exposure is likely to be immediately dangerous for any unprotected occupants trapped at this location. In fact, the heat exposure is about five times larger than in Test Type 2 and about 30 times larger than in Test Type 1. Additionally, skin surface temperature at Location 3 reaches approximately $50^{\circ} \mathrm{C}$ 

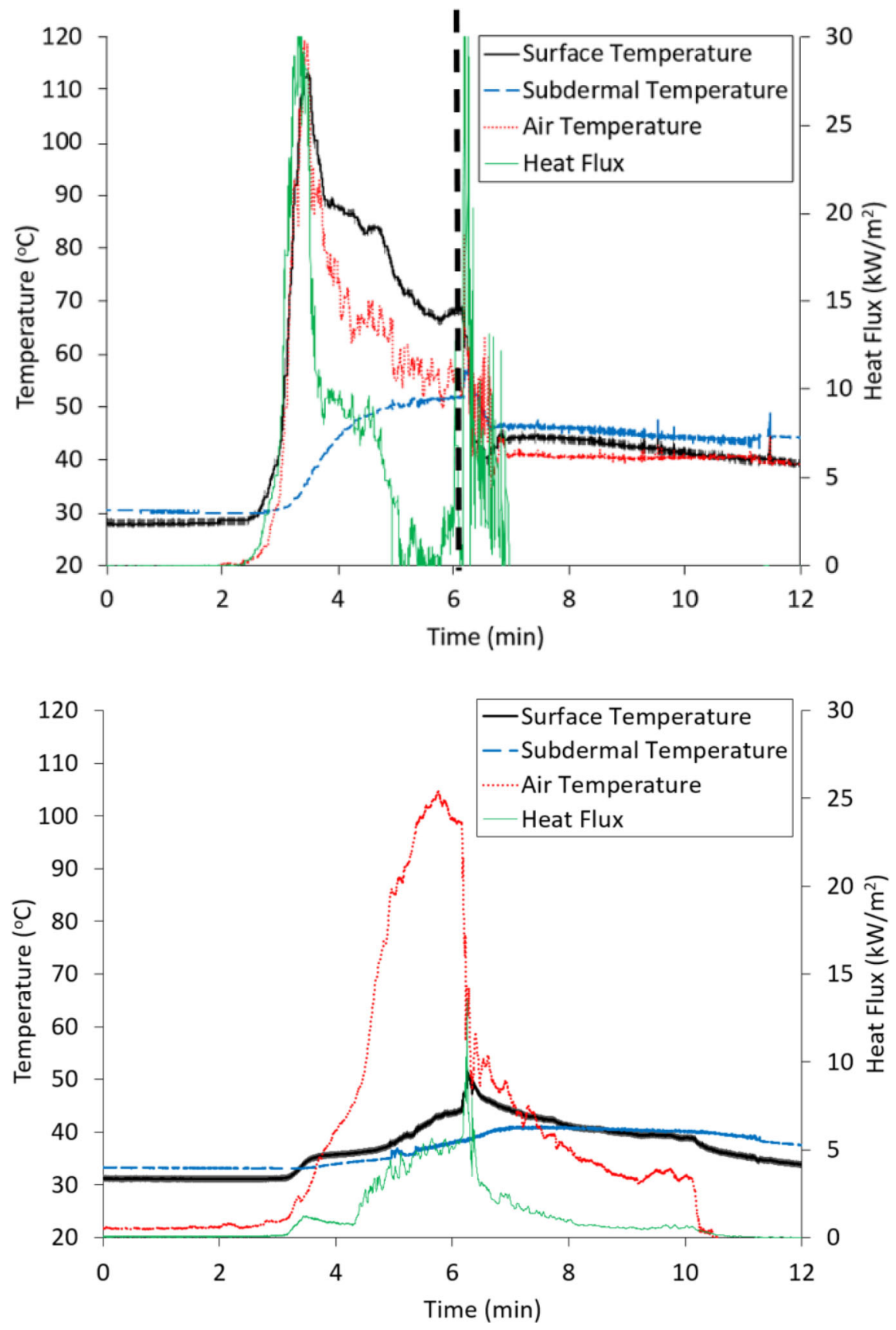

Figure 6. Average surface and subdermal temperature along with air temperature and local heat flux for Test Type 3 at SBA Location 1 (top) and Location 3 (bottom). Black dotted line shows water application time. 
in less than 6 min after ignition, which could also result in burns for trapped occupants at those locations. While the total heat flux in the target bedroom was much lower, the air temperature peaks around $100^{\circ} \mathrm{C}$ to $120^{\circ} \mathrm{C}$ at both locations. Interestingly, because of the extremely high temperature prior to water application, there were minimal temperature increases observed after suppression in this experiment. At Location 1, skin surface temperatures dropped immediately, despite the unrealistic changes in heat flux post suppression (peaking at $\sim 34 \mathrm{~kW} /$ $\mathrm{m}^{2}$ ). Skin temperature at Location 3 displayed a jump in magnitude for a few seconds that does coincide with an increase in heat flux, but a drop in ambient air temperature.

As Figs. 4, 5 and 6 display, the response of the skin surface and subdermal temperatures do not consistently scale or even trend with the traditional ambient air or heat flux measurements commonly used to estimate occupant burn risk. Due to the moisture in the fire environment, the heat flux gauges often significantly overpredict the skin temperatures after the hot upper gas layer descends to the height of the gauge. Furthermore, once water is applied to the fire, heat flux measurements made by water cooled gauges, particularly those near the fire room, are widely variable and not likely reliable for the estimation of heat transfer to skin tissues.

\subsection{Prior to Firefighter Intervention}

The relative impact of fire size and ventilation configuration on temperatures in unprotected skin at each simulated occupant location prior to fire service intervention is summarized in Table 2, including average and standard deviation of the surface and subdermal temperatures for each test type. As expected, the highest temperatures were measured at Location 1 followed by Location 3. The magnitudes measured during Test Type 1 and 2 might suggest occupants at Location 1 would experience pain with a possibility of first-degree burns prior to firefighter intervention for the average case, though there is a slightly higher risk for the vented fire configuration. On the other hand, based on measured subdermal temperatures, the two room fires (Test Type 3) likely resulted in increased risk for deeper

\section{Table 2}

SBA Surface and Subdermal Temperatures at Each Location and All Three Fire and Ventilation Configurations Prior to Any Fire Service Intervention (5:20 After Ignition)

\begin{tabular}{clccccc}
\hline & $\begin{array}{c}\text { Location 1 } \\
(\text { Mean } \pm \text { SD) }\end{array}$ & $\begin{array}{c}\text { Location 2 } \\
(\text { Mean } \pm \text { SD })\end{array}$ & $\begin{array}{c}\text { Location 3 } \\
(\text { Mean } \pm \text { SD) }\end{array}$ & $\begin{array}{c}\text { Location 4 } \\
(\text { Mean } \pm \text { SD) }\end{array}$ & $\begin{array}{c}\text { Location 5 } \\
(\text { Mean } \pm \text { SD) }\end{array}$ \\
\hline Test & Surface & $42.4 \pm 4.6$ & $31.1 \pm 2.4$ & $33.1 \pm 2.0$ & $32.0 \pm 2.0$ & $31.7 \pm 3.2$ \\
type 1 & Subdermal & $35.5 \pm 2.5$ & $31.8 \pm 1.7$ & $32.2 \pm 1.8$ & $31.8 \pm 2.9$ & $30.0 \pm 1.4$ \\
Test & Surface & $45.7 \pm 4.1$ & $28.9 \pm 2.7$ & $31.4 \pm 2.1$ & $29.5 \pm 1.6$ & $31.2 \pm 2.9$ \\
type 2 & Subdermal & $34.9 \pm 2.1$ & $31.2 \pm 1.3$ & $31.3 \pm 2.3$ & $28.8 \pm 1.7$ & $30.9 \pm 3.2$ \\
Test & Surface & $69.0 \pm 20.2$ & $30.5 \pm 2.8$ & $41.5 \pm 4.6$ & $32.1 \pm 2.8$ & $30.4 \pm 1.7$ \\
type 3 & Subdermal & $48.9 \pm 5.5$ & $31.7 \pm 2.8$ & $33.7 \pm 1.9$ & $32.0 \pm 1.5$ & $30.2 \pm 2.0$ \\
\hline
\end{tabular}


burns (deep second-degree or third-degree) for unprotected skin at Location 1 (subdermal temperatures above $44^{\circ} \mathrm{C}$ ) and possibly first-degree burns at Location 3 for a few of the higher temperature scenarios. In all other locations, skin temperatures are only slightly increased from baseline on the skin. In fact, in Location 2 (behind a closed bedroom door), subdermal temperatures remain higher than the surface temperatures. These results again reinforce the ability of a closed door to protect these simulated occupant locations from thermal burns [41]. It is important to note that perfusion and perspiration in live skin will likely reduce these temperature and can be incorporated in future work through numerical interpretation of these experimental data [e.g. 42, 43].

\subsection{Temperature Changes with Suppression}

A primary goal for developing this new assessment technique was to examine the relative impact of different fire attack methods on burn risk for potentially trapped occupants. Critically, the fire service discussion regarding interior vs exterior water application has often centered on the concerns that applying water from the exterior will increase the risk for injuring occupants trapped within the structure immediately after water application. To assess this impact, we specifically focused on changes at the SBA packages immediately after fire suppression.

Data are presented here in a relative format - to compare changes in the conditions after fire attack relative to those present immediately prior to water application. As has been shown before [41], despite the controlled laboratory environment within which these full-sized structure fires were conducted, there was important variability in fire development at the time of water application that could make comparison of raw magnitudes misleading. These data are grouped based on Test Type (1-3) and fire attack method (interior only vs exterior-to-exterior) where applicable. Table 3 shows the temperatures immediately before water is applied, the peak temperature increase after the initial water application (within $30 \mathrm{~s}$ ), and the difference in skin temperature at $30 \mathrm{~s}$ post-water application (compare to pre-water application) for each of the 21 scenarios where rapid fire service suppression was initiated after front door opening. Additionally, results from the delayed intervention experiments for each fire type are shown in the table in bold font (see Fig. 1 for timing details). Outside of delayed intervention scenarios, temperatures at Locations 2, 4, and 5 did not approach the $44^{\circ} \mathrm{C}$ surface temperature threshold where risk of skin burns would become a concern. Therefore, the rest of this discussion will focus on responses from the SBA packages at Locations 1 and 3 .

As summarized in Table 3, fire service water application has the potential to result in transient increases in skin temperatures for trapped occupants after either exterior or interior fire attack and even in rooms adjacent to the fire compartment (Location 3). The transient increases in temperature after rapid fire service intervention range from $0.0^{\circ} \mathrm{C}$ to $15.0^{\circ} \mathrm{C}$ for Location 1 (though peaked at a $33.3^{\circ} \mathrm{C}$ increase for delayed intervention for Test Type 3) and $0.5^{\circ} \mathrm{C}$ to $13.6^{\circ} \mathrm{C}$ for Location 3. At Location 1, for Type 1 fires, temperatures pre-water application were $43.2 \pm 1.5^{\circ} \mathrm{C}$ and the peak post-suppression temperature increase was 


\section{Table 3}

SBA Package Surface Temperature Changes ( $\left.{ }^{\circ} \mathrm{C}\right)$ Based on Fire Type and Fire Attack Method After Initial Water Application, Including Peak Temperature Increase Post-suppression and the Overall Change from Pre-water Application Temperafures 30 s Post-suppression. See Reference [38] for More Details on Timing of Each Experiment

\begin{tabular}{|c|c|c|c|c|c|c|c|c|}
\hline \multirow[b]{2}{*}{$\begin{array}{l}\text { Test } \\
\text { type }\end{array}$} & \multirow[b]{2}{*}{$\begin{array}{l}\text { Fire attack } \\
\text { method }\end{array}$} & \multirow[b]{2}{*}{$\begin{array}{c}\text { Experiment } \\
\quad \#[38]\end{array}$} & \multicolumn{3}{|c|}{ Occupant location 1} & \multicolumn{3}{|c|}{ Occupant location 3} \\
\hline & & & $\begin{array}{c}\text { Pre } \\
\text { water }\end{array}$ & $\begin{array}{c}\text { Peak increase } \\
\text { post-water }\end{array}$ & $\begin{array}{l}\text { Change } \\
\text { after } 30 \mathrm{~s}\end{array}$ & $\begin{array}{c}\text { Pre } \\
\text { water }\end{array}$ & $\begin{array}{c}\text { Peak } \\
\text { increase } \\
\text { post-water }\end{array}$ & $\begin{array}{l}\text { Change } \\
\text { after } 30 \mathrm{~s}\end{array}$ \\
\hline \multirow[t]{6}{*}{1} & \multirow[t]{5}{*}{ Interior } & 2 & 42.1 & 14.3 & -2.5 & 38.0 & 5.8 & 3.1 \\
\hline & & 3 & 42.9 & 10.5 & -0.3 & 49.4 & 0.5 & -1.8 \\
\hline & & $\overline{4}$ & $\overline{45.9}$ & $\overline{7.5}$ & $\overline{-14.2}$ & $\overline{50.5}$ & $\overline{1.9}$ & $\overline{-1.3}$ \\
\hline & & 5 & 42.7 & 4.7 & 2.4 & 42.6 & 0.7 & 0.3 \\
\hline & & 6 & 42.5 & 11.9 & 0.5 & 48.1 & 3.7 & -0.7 \\
\hline & Delayed & 1 & 136.6 & 3.4 & -71.9 & 67.4 & 1.0 & 0.6 \\
\hline \multirow[t]{10}{*}{2} & \multirow[t]{5}{*}{ Interior } & 7 & 50.2 & 3.7 & -5.5 & 34.6 & 4.3 & 1.8 \\
\hline & & 8 & 45.4 & 4.2 & -2.0 & 31.5 & 4.8 & 0.3 \\
\hline & & 9 & 42.1 & 7.4 & -6.7 & 29.9 & 7.4 & 2.7 \\
\hline & & 10 & 47.2 & 7.1 & -1.5 & $\underline{32.7}$ & $\underline{5.5}$ & 0.9 \\
\hline & & $\overline{11}$ & $\overline{44.8}$ & $\overline{3.6}$ & -5.3 & $\overline{31.0}$ & $1 \overline{0.4}$ & $\overline{1.7}$ \\
\hline & \multirow{4}{*}{$\begin{array}{l}\text { Exterior- } \\
\text { to-Interior }\end{array}$} & 18 & 47.2 & 15.0 & -4.2 & 33.2 & 1.5 & 1.1 \\
\hline & & 19 & 41.9 & 3.2 & -4.0 & 31.2 & 1.4 & 1.2 \\
\hline & & 20 & 45.8 & 0.3 & -3.6 & 33.6 & 1.9 & 1.9 \\
\hline & & 21 & 43.9 & 0.1 & -5.1 & 30.8 & 1.3 & 0.8 \\
\hline & Delayed & 12 & 104.3 & 1.0 & -56.2 & 53.5 & 2.1 & 2.1 \\
\hline \multirow[t]{8}{*}{3} & \multirow[t]{4}{*}{ Interior } & 13 & 66.6 & 2.1 & -25.5 & 43.6 & 7.7 & 2.4 \\
\hline & & $\overline{14}$ & $\overline{53.4}$ & $\overline{8.2}$ & -9.1 & $\overline{51.6}$ & $\overline{3.8}$ & $-\overline{2.1}$ \\
\hline & & 15 & 56.6 & 8.9 & -8.0 & 40.2 & 7.6 & 3.1 \\
\hline & & 16 & 73.5 & 0.2 & -29.5 & 39.7 & 13.6 & 0.0 \\
\hline & Exterior- & 22 & 93.2 & 0.0 & -12.6 & 49.1 & 1.4 & -3.9 \\
\hline & \multirow[t]{2}{*}{ to-Interior } & 23 & 59.3 & 5.9 & 5.3 & 41.8 & 1.9 & -2.9 \\
\hline & & 24 & 95.7 & 4.0 & -29.6 & 40.2 & 1.4 & 1.3 \\
\hline & Delayed & 17 & 214.6 & 33.3 & -169.7 & 51.4 & 1.0 & -2.6 \\
\hline
\end{tabular}

Data shown in underlined font are from the same set as shown in Figs. 4, 5 and 6. Data shown in bold is from the Delayed scenario for ease of reference

$9.8 \pm 3.7^{\circ} \mathrm{C}$. For Type 2 fires at Location 1, pre-suppression temperatures were $45.9 \pm 3.0^{\circ} \mathrm{C}$ with a $5.2 \pm 1.9^{\circ} \mathrm{C}$ peak increase for interior fire attack scenarios while these magnitudes were very similar at $44.7 \pm 2.3^{\circ} \mathrm{C}$ and $4.7 \pm 7.0^{\circ} \mathrm{C}$ after the initial exterior water application in the exterior-to-interior fire attack scenarios. Type 3 fires resulted in pre-suppression temperatures of $62.5 \pm 9.2^{\circ} \mathrm{C}$ with a $4.9 \pm 4.4^{\circ} \mathrm{C}$ peak increase for interior fire attack scenarios compared to pre-suppression temperatures of $82.7 \pm 20.3^{\circ} \mathrm{C}$ and $3.3 \pm 3.0^{\circ} \mathrm{C}$ peak increase after the initial exterior water application in the at Location 1. When all of the Test Type 2 and 3 scenarios tested here are combined, there were no statistically significant differences observed between the temperature increases at the test location immediately outside of the fire room(s) regardless of utilizing the exterior or interior fire 
stream. This study provides the first indication of transient increases in skin surface temperature on the order of $5^{\circ} \mathrm{C}$ that result from fire suppression streams. At the same time, the delayed suppression experiments provide important context for these results, where skin temperature increases due to the increased fire exposure were up to an order of magnitude larger than that which results from suppression streams.

At Location 3, for Test Type 1 fires, temperatures pre-water application were $45.7 \pm 5.3^{\circ} \mathrm{C}$ and the peak temperature change post suppression was $2.5 \pm 2.2^{\circ} \mathrm{C}$. For Type 2 fires, pre-fire temperatures were $31.9 \pm 1.8^{\circ} \mathrm{C}$ with a $6.5 \pm 2.5^{\circ} \mathrm{C}$ peak for interior fire attack scenarios and $32.2 \pm 1.4^{\circ} \mathrm{C}$ with $1.5 \pm 0.3^{\circ} \mathrm{C}$ peak increase after the initial exterior water application. Finally, for Type 3 fires pre-fire temperatures were $43.8 \pm 5.5^{\circ} \mathrm{C}$ with a $8.2 \pm 4.1^{\circ} \mathrm{C}$ peak for interior suppression scenarios and $43.7 \pm 4.7^{\circ} \mathrm{C}$ with a $1.6 \pm 0.3^{\circ} \mathrm{C}$ peak increase after the initial exterior water application. When all the Test Type 2 and 3 scenarios are combined, the peak temperature increase after the exterior water application was slightly, but significantly lower than after the initial interior fire attack at Location 3 $(p=0.001)$.

There are several potential mechanisms that may be responsible for these transient increases in temperature, such as steam and/or hot water coming in contact with the surface of the skin, particularly at Location 1. It is also possible that this effect may be attributable to the hot gas layer descending onto the surface of the skin as it is cooled by suppression streams, which can provide for increased convective heat flow to the skin while also allowing in the high water vapor content in the upper layer an opportunity to condense onto the cooler skin surface. This mechanism is likely most relevant at Location 3 where the samples were elevated. Further study is necessary to elucidate the mechanism by which this heat transfer is occurring. However, the finding that water application in the fire environment can cause transients to occur regardless of the orientation of the suppression stream, is a critical message to convey to the fire service.

At the same time, it is important to note that in 19 of the 21 scenarios, rapid application of water to the fire resulted in either a reduction in surface temperature or minimal temperature changes within $30 \mathrm{~s}$ of initial water applications at the simulated occupant in the highest thermal risk (Location 1). Despite the transient increase shortly after fire attack, the water application was able to either reduce or minimize the increase in temperatures that would be experienced if water were not applied. At Location 3, the temperature changes $30 \mathrm{~s}$ after water application range from $-3.9^{\circ} \mathrm{C}$ to $+3.1^{\circ} \mathrm{C}$. However, again at Location 3 , the skin temperatures $30 \mathrm{~s}$ after water application were below the skin temperatures prior to water application in the delayed water application experiments.

Despite these consistent trends, there were two scenarios where the skin temperature $30 \mathrm{~s}$ after water application was more than $1{ }^{\circ} \mathrm{C}$ higher than prior to water application at Location 1 (Experiment 5-Test Type 1, interior fire attack and Experiment 23-Test Type 3, exterior-to-interior fire attack). In both scenarios, the fire attack was conducted using a narrow fog pattern compared to a solid or straight stream for the others in those groups of scenarios. A similar narrow fog pattern was utilized for other Test Type 2 (Experiment 11 and 19) and Test Type 
3 (Experiment 16) scenarios, where the temperature was significantly reduced at Location 1 within $30 \mathrm{~s}$. As such, these increased temperatures are not consistent across all narrow fog scenarios. However, Experiment 11 and 16 resulted in the largest peak increase post-water at Location $3\left(10.4^{\circ} \mathrm{C}\right.$ and $\left.13.6^{\circ} \mathrm{C}\right)$; the only two scenarios with peak temperature increases that were more than two standard deviations from the mean of all 24 scenarios at Location $3\left(4.0 \pm 3.2^{\circ} \mathrm{C}\right)$. While these four (of the five total) scenarios utilizing narrow fog stream patterns produce interesting observations, additional controlled experiments are necessary to fully vet the impact of stream pattern on skin temperature change.

While short-lived transient increases in surface temperature were noted after water was applied to the fire-and in some cases may increase the level of risk for burn injuries to trapped occupants - it is important to put this in context of what might happen without fire service intervention. Table 4 shows the peak surface and subdermal temperatures at Location 1 averaged over all the rapid fire service intervention scenarios (i.e. fire attack using interior only or exterior-to-interior means shortly after the front door is open) compared to the scenarios where the fire service intervention was delayed. Peak temperatures suggest that occupants with exposed skin may be at risk for first-degree or possibly second-degree burns for the one bedroom fires and likely third-degree or deeper burns for the two bedroom fires after fire service intervention. However, if suppression is delayed for the Test Type 1 and 2 fires, skin temperatures can reach values similar to or higher than the multi-room fires (Test Type 3) and the occupant would be at risk for third-degree or deeper burns. At the same time, a $4 \mathrm{~min}$ to $5 \mathrm{~min}$ delay in water application for the two bedroom fire (Test Type 3) resulted in surface and subdermal temperatures that would likely cause significant damage to deep biological tissues. Thus, while water application was shown to result in transient increases in skin surface temperature, a delay of a few minutes results in significantly higher risk for burns near the fire room $(s)$.

Table 5 shows the same comparison, but at Location 3 (in the target bedroom). Test Type 1 and 3 typically resulted in skin temperatures that might suggest a risk for first- or second-degree burns for exposed skin. Again, delayed water application significantly increased risk for deeper burns at each location for Test Types 1 and 2. Test Type 3 did not show a significant difference in temperatures for the

\section{Table 4}

\section{Average Peak Surface and Subdermal Temperatures ( $\left.{ }^{\circ} \mathrm{C}\right)$ for Different Test Types with Quick and Delayed Interventions for Location 1}

\begin{tabular}{lccccc}
\hline & \multicolumn{2}{c}{ Dermal surface temperature } & & \multicolumn{2}{c}{ Subdermal temperature } \\
\cline { 2 - 3 } \cline { 5 - 6 } $\begin{array}{l}\text { Test } \\
\text { type }\end{array}$ & $\begin{array}{l}\text { Fire service } \\
\text { intervention }\end{array}$ & $\begin{array}{c}\text { Delayed } \\
\text { suppression }\end{array}$ & & $\begin{array}{c}\text { Fire service } \\
\text { intervention }\end{array}$ & $\begin{array}{c}\text { Delayed } \\
\text { suppression }\end{array}$ \\
\hline 1 & $50.9 \pm 6.0$ & 140.0 & & $43.5 \pm 2.0$ & 72.3 \\
2 & $51.2 \pm 5.4$ & 107.2 & & $39.7 \pm 2.3$ & 66.5 \\
3 & $97.3 \pm 25.5$ & 248.0 & & $55.9 \pm 4.7$ & 78.6 \\
\hline
\end{tabular}




\section{Table 5 \\ Average Maximum Surface and Subdermal Temperatures $\left({ }^{\circ} \mathrm{C}\right)$ for Different Test Types with Quick and Delayed Interventions for Location 3}

\begin{tabular}{lccccc}
\hline & \multicolumn{2}{c}{ Dermal surface temperature } & & \multicolumn{2}{c}{ Subdermal temperature } \\
\cline { 2 - 3 } \cline { 5 - 6 } $\begin{array}{l}\text { Test } \\
\text { type }\end{array}$ & $\begin{array}{l}\text { Fire service } \\
\text { intervention }\end{array}$ & $\begin{array}{c}\text { Delayed } \\
\text { suppression }\end{array}$ & & $\begin{array}{c}\text { Fire service } \\
\text { intervention }\end{array}$ & $\begin{array}{c}\text { Delayed } \\
\text { suppression }\end{array}$ \\
\hline 1 & $47.5 \pm 4.3$ & 68.8 & & $42.0 \pm 4.1$ & 62.4 \\
2 & $38.7 \pm 3.8$ & 56.9 & & $34.7 \pm 2.7$ & 49.6 \\
3 & $52.1 \pm 4.3$ & 52.8 & & $40.4 \pm 3.0$ & 40.3 \\
\hline
\end{tabular}

delayed water application likely due to the increased ventilation of both bedroom windows preventing heat from reaching Location 3. The highest temperatures recorded at this location were for the Test Type 1 delayed water application experiment due to the length of time that this simulated occupant location was subjected to the hot gases. In addition to the added thermal risk from the delayed intervention, the relative magnitude of the toxic gas concentrations will also increase and are likely important at Location 3, which is elevated on the bed.

\section{Future Work}

The experimental platform introduced here can provide important additional insights related to skin burn risk for occupants of a structure as well as firefighters responding to these incidents. Future studies with the SBA tool can include the impact of sleepwear or other clothing that may influence burn risk for trapped occupants or how different levels of firefighting PPE can impact firefighters' burn risk. This tool provides information that may be more relatable and understandable that typical TPP tests (and may be conducted with different levels of moisture in the air). Future studies should also include model based interpretation of the experimental data. Such analysis techniques may range from simple extrapolations of the Henriques model using surface temperature measurements to more advanced finite element modeling that can elucidate the physics and physiology of the burn process in more detail. Furthermore, the SBA tool provides a direct measurement of subdermal temperatures, which may also be used to estimate damage evolution through the dermal layer thickness. Such efforts should be supported and validated by laboratory scale experiments that measure temperature change through the depth of the skin surrogate in a variety of convective and radiant conditions with a range of moisture concentrations that may be experienced during fire conditions (this effort will be enabled by an ongoing study to measure moisture concentrations during similar full scale experiments [38]). The tool itself may be iterated to include skin surrogates such as hydrogel or other materials that can experimentally include controlled levels of perfusion and possibly even blister- 
ing in a material system that precludes the need to harvest and process porcine skin (which can be a limiting step for broad implementation of the tool).

\section{Conclusions}

By deploying a novel experimental method using an ex vivo porcine skin model in a series of full-scale residential structure fire scenarios, new information regarding thermal exposure risk to trapped occupants has been presented. Importantly, skin temperature changes did not consistently correlate with ambient temperature measurement from a bare bead thermocouple or heat flux measurements, which are commonly used in standardized risk assessment approaches. Differences with heat flux measurements were particularly noteworthy after fire service water application, which was the source of risk of interest here.

Using the porcine skin model, water application in the full-scale residential structure fire scenarios was found to result in short lived, transient increases in surface temperature on the order of $5^{\circ} \mathrm{C}$ near the fire rooms. In nearly all scenarios tested, by $30 \mathrm{~s}$ after water application, the skin surface temperatures were lower than or similar to the magnitude prior to firefighter intervention. There was no significant difference in the magnitude of these temperature changes shortly after water was applied to the fire from the exterior or the interior at the location immediately outside the fire room, though slightly lower peak skin temperature increases were measured in the target bedroom after the exterior fire attack. This finding is important to the fire service in the on-going conversation regarding tactical decision as well as to practicing fire protection engineers in characterizing tenability changes during suppression (manual and installed systems). Importantly, it was also found that delaying the application of water to the fire (in some cases by just a few minutes after opening the front door) resulted in the highest skin surface temperatures and presented the highest burn risk to occupants.

Not only does this tool provide new and useful insight for the fire service to further understand the impact of fire suppression steams on occupant burn risk, but with additional model based interpretation supported by laboratory scale assessments, it may provide a platform for a variety of future investigations related to both occupant and firefighter burn risk.

\section{Acknowledgements}

This work was supported by the Department of Homeland Security Fire Prevention and Safety Grant \# EMW-2013-FP-00644. The authors would like to thank the UL FSRI engineering team and UL LLC lab staff for their assistance in setting up and conducting the full scale house burns. 


\section{Open Access}

This article is distributed under the terms of the Creative Commons Attribution 4.0 International License (http://creativecommons.org/licenses/by/4.0/), which permits unrestricted use, distribution, and reproduction in any medium, provided you give appropriate credit to the original author(s) and the source, provide a link to the Creative Commons license, and indicate if changes were made.

\section{References}

1. Kerber S, Walton WD (2005) Effect of positive pressure ventilation on a room fire, NISTIR 7213. National Institute of Standards and Technology, Gaithersburg

2. Svensson S (2001) Experimental study of fire ventilation during fire fighting operations. Fire Technol 37:69-85

3. Kerber S, Walton WD (2006) Full-scale evaluation of positive pressure ventilation in a fire fighter training building, NISTIR 7342. National Institute of Standards and Technology, Gaithersburg

4. Kerber S (2010) Impact of ventilation on fire behavior in legacy and contemporary residential construction. Underwriters laboratories, Northbrook. https://ulfirefightersafety. org/docs/DHS_2008_Grant_Report_Final.pdf. Accessed 3 June 2019

5. Kerber S (2012) Study of the effectiveness of fire service vertical ventilation and suppression tactics in single family homes, UL Firefighter Safety Research Institute, Northbrook. https://ulfirefightersafety.org/docs/UL-FSRI-2010-DHS-Report_Comp.pdf. Accessed 3 June 2019

6. Layman L (1952) Attacking and extinguishing interior fires. National Fire Protection Association, Boston

7. Svensson S, Särdqvist S (2001) Fire tests in a large hall, using manually applied highand low pressure water sprays. Fire Sci Technol 21(1):1-17

8. Traina N, Kerber S, Kyritsis DC, Horn GP (2017) Occupant tenability in single family homes Part II: impact of door control, vertical ventilation, and water application. Fire Technol 53(4):1611-1640

9. Purchase D (2012) Offensive exterior operations, a new approach. Firefighternation.com. https://www.firerescuemagazine.com/articles/print/volume-7/issue-10/firefighting-o perations/offensive-exterior-operations-a-new-approach.html. Accessed 3 June 2019

10. Kanterman R (2013) The suppression aggression olympics. Fire Engineering.com. http s://www.fireengineering.com/articles/2013/11/the-suppresion-agression-olympics.html.

Accessed 3 June 2019

11. Schwarz LG, Wheeler D (2009) Transitional fire attack. Fire Engineering.com Downloaded from: https:/www.fireengineering.com/articles/print/volume-162/issue-110/featur es/transitional-fire.html. Accessed 3 June 2019

12. Cotter MJ (2015) MFA \#17: The "Steaming Victims" Issue: How water flow makes everything better at a fire. FireEngineering.com Downloaded from: https://community.f ireengineering.com $/$ profiles $/ \mathrm{blog} / \mathrm{show}$ id $=1219672 \% 3 \mathrm{ABlogPost} \% 3 \mathrm{~A} 624426$. Accessed 3 June 2019

13. Lee JL (2015) Why firefighters get steam burns: exploratory study underway. NIST News. https://www.nist.gov/news-events/news/2015/04/why-firefighters-get-steam-burnsexploratory-study-underway. Accessed 3 June 2019 
14. Norman J (2012) Fire officer's handbook of tactics, 2nd edn. Fire Engineering Books and Videos, Pennwell, Tulsa, p. 50

15. ISO 13571 (2010) Life-threatening components of fire - Guidelines for the estimation of time to compromised tenability in fires. International Organization for Standardization, Geneva

16. Purser DA (2000) Toxic product yields and hazard assessment for fully enclosed design fires. Polym Int 49(10):1232-1255

17. Crewe RJ, Stec AA, Walker RG, Shaw JE, Hull TR, Rhodes J, Garcia-Sorribes T (2014) Experimental results of a residential house fire test on tenability: temperature, smoke, and gas analyses. J Forensic Sci 59(1):139-154

18. Guillaume E, Didieux F, Thiry A, Bellivier A (2014) Real-Scale fire tests of one bedroom apartments with regard to tenability assessment. Fire Safety J 70:81-97

19. Su JZ, Benichou N, Bwalya AC, Lougheed GD, Taber BC, Leroux P (2010) Tenability analysis for fire experiments conducted in a full-scale test house with basement fire scenarios. NRCC-53273 National Research Council of Canada, Ottawa

20. Willi JM, Horn GP, Madrzykowski D (2016) Characterizing a firefighter's immediate thermal environment in live-fire training scenarios. Fire Technol 52(6):1339-1350

21. Hardy JD, Muschenheim C (1934) The radiation of heat from the human body IV The emission, reflection, and transmission of infra-red radiation by the human skin. J Clin Invest 13(5):817-831

22. Hardy JD, Hammel HT, Murgatroyd D (1956) Spectral transmittance and reflectance of excised human skin. J Appl Physiol 9(2):257-264

23. McGrath JA, Uitto J (2010) Anatomy and organization of human skin. In: Burns T, Breathnach S, Cox N, Griffiths C (eds) Rook's textbook of dermatology, 8th edn. Blackwell, Hoboken, pp 3.1-3.53

24. Whitton JT, Everall JD (1973) The thickness of the epidermis. Br J Dermatol 89(5):467-476

25. Southwood WF (1955) The thickness of the skin. Plast Reconstr Surg 15(5):423-429

26. Hummel A, Barker R, Lyons K (2014) Skin burn translation model for evaluating hand protection in flash fire exposures. Fire Technol 50(5):1285-1299

27. Hoffmann K, Stücker M, Dirschka T, Görtz S, El-Gammal S, Dirting K, Hoffman A, Altmeyer P (1994) Twenty MHz B-scan sonography for visualization and skin thickness measurement of human skin. J Eur Acad Dermatol Venereol 3(3):302-313

28. Forage AV (1963) The history of the classification of burns (Diagnosis of depth). Br J Plast Surg 16(C):239-242

29. Brownson EG, Gibran NS (2018) Evaluation of the burn wound: management decisions. In: Herndon DN (ed) Total burn care, 2th edn. Elsevier, Amsterdam, pp 8792.e2

30. Berry J, Mancini M (2018) Classification of Burns. University of Rochester Medical Center: Health Encyclopedia. Downloaded from: https://www.urmc.rochester.edu/encyc lopedia/content.aspx?ContentTypeID $=90 \&$ ContentID $=$ P09575. Accessed 3 June 2019

31. Moritz AR, Henriques FC Jr (1947) Studies of thermal injury II: the relative importance of time and surface temperature in the causation of cutaneous burns. Am $\mathbf{J}$ Pathol 23(5):695-720

32. Douglas WR (1972) Of pigs and men and research: a review of applications and analogies of the pig, sus scrofa, in human medical research. Space Life Sci 3(3):226-234

33. Sheu S-Y, Wang W-L, Fu Y-T, Lin S-C, Lei Y-C, Liao J-H, Tang N-Y, Kuo T-F, Yao C-H (2014) The pig as an experimental model for mid-dermal burns research. Burns 40(8):1679-1688 
34. SullivanTP Eaglstein WH, Davis SC, Mertz P (2001) The pig as a model for human wound healing. Wound Repair Regen 9(2):66-76

35. Smith KJ, Graham JS, Skelton HG, Hamilton T, O'Leary T, Okerberg CV, Moeller R, Hurst CG (1998) Sensitivity of cross-reacting antihuman antibodies in formalin-fixed porcine skin: Including antibodies to proliferation antigens and cytokeratins with specificity in the skin. J Dermatol Sci 18(1):19-29

36. Henriques FC (1947) Studies of thermal injury. V. The predictability and significance of thermally induced rate processes leading to irreversible epidermal injury. Arch Path 43:489-502

37. Stoll AM, Greene LC (1959) Relationship between pain and tissue damage due to thermal radiation. J Appl Physiol 14(3):373-382

38. Zevotek R, Stakes K, Willi J (2018) Impact of Fire attack utilizing interior and exterior streams on firefighter safety and occupant survival: full scale experiments. Firefighter Safety Research Institute. Underwriters Laboratories. https://ulfirefightersafety.org/docs /DHS2013_Part_III_Full_Scale.pdf. Accessed 3 June 2019

39. Nakos JT (2004) Uncertainty analysis of thermocouple measurements in normal and abnormal thermal environment experiments at Sandia's radiant heat facility and Lurance Canyon Burn Site, SAND2004-1023. Sandia National Laboratories, Albuquerque

40. Donnely MK, Davis WD, Lawson JR, Selepak MJ (2006). Thermal environment for electronic equipment used by first responders. NIST Technical Note 1474 National Institute of Standards and Technology, Gaithersburg

41. Traina N, Kerber S, Kyritsis DC, Horn GP (2017) Occupant tenability in single family homes: Part I-impact of structure type, fire location and interior doors prior to fire department arrival. Fire Technol 53(4):1589-1610

42. Torvi DA, Dale JD (1994) A finite element model of skin subjected to a flash fire. J Mech Eng 116:250-255

43. Abraham JP, Sparrow EM (2007) A thermal-ablation bioheat model including liquidto-vapor phase change, pressure- and necrosis-dependent perfusion, and moisture-dependent properties. Int J Heat Mass Trans 50:2537-2544

Publisher's Note Springer Nature remains neutral with regard to jurisdictional claims in published maps and institutional affiliations. 